\title{
Low prevalence of fetal-type posterior cerebral artery in patients with basilar tip aneurysms
}

\author{
Mariana C Diogo, ${ }^{1}$ Isabel Fragata, ${ }^{1}$ Sara P Dias, ${ }^{2}$ Joana Nunes, ${ }^{3}$ Jaime Pamplona, ${ }^{1}$ \\ João Reis ${ }^{1}$
}

${ }^{1}$ Neuroradiology Department, Centro Hospitalar de Lisboa Central, Lisboa, Portugal

${ }^{2}$ Neurology Department, Centro Hospitalar de Lisboa Central, Lisboa, Portugal

${ }^{3}$ Neuroradiology Department, Centro Hospitalar de Vila Nova de Gaia/Espinho, Gaia, Portugal

\section{Correspondence to}

Dr Mariana Cardoso Diogo, Neuroradiology Department, Centro Hospitalar de Lisboa Central, Rua José António Serrano, Lisboa 1150-199, Portugal; mariana.cardoso. diogo@gmail.com

Received 10 May 2016 Revised 11 June 2016 Accepted 14 June 2016

To cite: Diogo MC, Fragata I, Dias SP, et al. J Neurolntervent Surg Published Online First: [please include Day Month Year] doi:10.1136/

neurintsurg-2016-012503

\section{ABSTRACT}

Background Basilar tip aneurysms (BTA) are multifactorial in origin, with luminal forces playing a major role in their formation. Considering the reduced hemodynamic stress on the basilar apex in the fetal-type posterior cerebral artery (fPCA), we hypothesize that BTA should be less common in patients with this variant. Objective To investigate, in a retrospective casecontrol study, the frequency of fPCA in patients with and without BTA.

Materials and methods We collected clinical and imaging data from consecutive patients with BTA undergoing catheter angiography between July 2010 and July 2015, and from a randomly selected, age- and sex-matched non-BTA control population from our prospective database. Anatomical variants of the distal basilar artery region were assessed in the two groups and compared using parametric and non-parametric tests.

Results Fifty-nine BTA cases and 337 controls were included. fPCA was present in $3 \%$ of patients with BTA and $23 \%$ in the control group ( $p<0.001 ; O R=0.11$, $95 \% \mathrm{Cl} 0.03$ to 0.48 ). Basilar tip disposition was cranial in $49 \%$ of BTA and $63 \%$ of non-BTA cases ( $p=0.04$; $\mathrm{OR}=0.57,95 \% \mathrm{Cl} 0.33$ to 0.99 ); a caudal disposition was found in $24 \%$ and $6 \%$ of cases, respectively ( $p<0.001 ; O R=4.65,95 \%$ Cl 2.21 to 9.80).

Conclusions We found a statistically significant association between the absence of PPCA and BTA. Our findings underline the importance of hemodynamic stress in the formation of intracranial aneurysms, and suggest that $\mathrm{PPCA}$ is a protective variant for formation of BTA.

\section{INTRODUCTION}

Intracranial aneurysms are vascular dilatations believed to arise from a focal weakness of the arterial wall. In the intracranial compartment, their prevalence increases with age and varies in different studies, ranging from $1 \%$ to $10 \%$, with saccular aneurysms accounting for $80-90 \%$ of all intracranial aneurysms. ${ }^{1}$ Although most aneurysms remain asymptomatic, a minority rupture, with high associated morbidity and mortality rates. ${ }^{2}{ }^{3}$ Posterior circulation aneurysms, such as basilar tip aneurysms (BTA), have a higher risk of rupture and are associated with a worse prognosis. ${ }^{3}$

Aneurysm formation is a complex and multifactorial process and its precise pathophysiology is still not entirely understood. ${ }^{124}$ Established modifiable risk factors include smoking, alcohol consumption, and hypertension, ${ }^{1-3}$ but genetic predisposition is also an important factor. ${ }^{2}{ }^{4}$ Hemodynamic forces also play a major role in aneurysm formation, enlargement, and rupture, with wall shear stress and transmural pressure linked to mechanical and molecular changes, ${ }^{4-9}$ triggering focal degenerative mechanisms at the vessel wall. ${ }^{10}$ Accordingly, saccular aneurysms are most commonly located at branching points of the major arteries, where hemodynamic stress is highest. ${ }^{5}$

The fetal origin of the posterior cerebral artery (fPCA) is a common anatomical variant of the circle of Willis, corresponding to a persistent embryonic derivation of the posterior cerebral artery (PCA) from the internal carotid artery (ICA). Although it strictly represents a failure of the posterior circulation to develop a connection between the precommunicating (P1) segment and the preexisting PCA, ${ }^{11}$ the term has been widely used to describe circles with hypoplastic P1 segments. These different definitions partially account for the reported wide variation in the prevalence of fPCA. ${ }^{12}{ }^{13}$ This anatomical configuration, in which the basilar artery (BA) feeds only perforators and the cerebellar arteries, has been proved to significantly reduce BA flow rates. ${ }^{14} 15$

We theorize that the PPCA variant by diminishing hemodynamic stress at the basilar apex wall, should confer relative protection against aneurysmal formation at the BA bifurcation.

The main purpose of our study was to compare the prevalence of FPCA in patients with and without BTA. A secondary aim was to compare the relative prevalence of unilateral, bilateral, and complete and partial APCA, as well as the type of BA fusion, in patients with and without BTA.

\section{MATERIALS AND METHODS \\ Materials/subjects}

In a retrospective case-control study, we analyzed consecutive patients with saccular BTA who underwent digital subtraction angiography (DSA) between July 2010 and July 2015 at the interventional neuroradiology unit of a tertiary hospital. Patients with non-saccular aneurysms or BA aneurysms in other segments were excluded. Demographic and clinical data were collected for each patient from medical records.

A group of age- and sex-matched patients without BTA who underwent cerebral DSA between January 2011 and July 2015 were randomly selected from our interventional neuroradiology prospective database and served as the control population. Patients aged $\geq 18$ years whose examinations had contrast injection on both ICAs and at least one vertebral 


\section{Neuroimaging}

Figure 1 Types of basilar fusion. Digital subtraction angiographyposteroanterior incidences with contrast injection in the vertebral artery ( $A$, right; $B, C$, left). (A) Symmetrical cranial fusion with both anterior superior cerebellar arteries (ASCAs) originating from the basilar trunk (black arrows). (B) Symmetrical caudal fusion, with both ASCAs originating from the posterior cerebral artery P1 segments (black arrows). (C) Symmetrical fusion with the right ASCA originating from the P1 on the right (white arrow) and from the basilar trunk on the left. Note the previously coiled basilar tip aneurysms (asterisk).

artery were included. Exclusion criteria included suboptimal image quality, previous intracranial surgery, and signs of intracranial hypertension, intracranial vascular occlusion, or vasospasm.

The relevant institutional review boards and ethics committees approved our research protocol.

\section{Imaging studies}

All DSA images were reviewed by two independent observers (MCD and IF), with 4 and 10 years' experience, respectively. Anatomical characteristics and variants of the distal BA region were assessed. We chose to classify fPCA in two subtypes; PCA fetal disposition was considered complete when there was aplasia of the precommunicating (P1) PCA segment, and partial when the P1 segment was hypoplastic (defined as an internal arterial diameter inferior to that of the ipsilateral PCA). ${ }^{14} \mathrm{BA}$ fusion type was classified as symmetrical or asymmetrical; symmetrical fusions were further subdivided into cranial if the superior cerebellar arteries (SCA) originated from the BA, or caudal if the SCA originated from the PCA (figure 1). ${ }^{11}$

\section{Statistical analysis}

Descriptive statistics were used to characterize the study population. Continuous variables are expressed as mean and SD. Categorical variables are expressed as absolute (n) and relative (\%) frequencies and were analyzed with the $\chi^{2}$ or Fisher exact tests, as appropriate. ORs and 95\% CIs were used to quantify the strength of associations. All statistical tests were two-tailed, and analyses were performed using IBM SPSS Statistics software (V.23.0), with significance level set at 0.05.

Table 1 Distribution of fetal-type posterior cerebral arteries

\begin{tabular}{lll}
\hline & BTA group $(\mathrm{n}=59)$ & Non-BTA group $(\mathrm{n}=337)$ \\
\hline Complete fPCA, $\mathrm{n}(\%)$ & 0 & $40(12)^{*}$ \\
Unilateral right, $\mathrm{n}(\%)$ & - & $22(7)$ \\
Unilateral left, $\mathrm{n}(\%)$ & - & $16(5)$ \\
Bilateral, $\mathrm{n}(\%)$ & - & $3(0.9)$ \\
Partial fPCA, $\mathrm{n}(\%)$ & $2(3)$ & $40(12)^{*}$ \\
Unilateral right, $\mathrm{n}(\%)$ & $1(2)$ & $18(5)$ \\
Unilateral left, $\mathrm{n}(\%)$ & 0 & $15(4)$ \\
Bilateral, $\mathrm{n}(\%)$ & $1(2)$ & $6(2)$ \\
\hline *One non-BTA case had a complete right fPCA and a partial left fPCA. \\
BTA, basilar tip aneurysm; fPCA, fetal-type posterior cerebral artery.
\end{tabular}

Sample size was calculated for an unpaired case-control study, with a CI of $95 \%$ and $80 \%$ power, using the OpenEpi calculator, V.3 (available at http://www.openepi.com/SampleSize/SSCC. htm).

\section{RESULTS}

Fifty-nine patients with a total of 59 BTA fulfilled the inclusion criteria. There was a female predominance, with $73 \%(n=43)$ of patients being women. Our control group comprised 337 patients, $212(63 \%)$ female. Mean age at DSA was $56 \pm 13$ (range 24-79) for the BTA group and 57 \pm 14 (range 20-85) for the control group.

Clinical presentation of BTA was subarachnoid hemorrhage in the majority of patients $(59 \%, n=35)$. Unruptured aneurysms were diagnosed on CT/MRI performed for other reasons in the remaining cases (table 1 ).

In the BTA group, no complete fPCA were identified (table 2). Partial fPCA were identified in two patients: one right unilateral fPCA (figure 2) and one bilaterally (figure 3).

A fPCA was identified in $23 \%(n=79)$ of patients in the non-BTA group; this finding was bilateral in $13 \%$ of them $(n=10)$ and complete in $49 \%(n=39)$. Basilar tip dispositions were also assessed as cranial, caudal, or asymmetrical. Findings are summarized in table 2 .

Table 2 BTA and non-BTA groups: demographic characteristics and basilar tip variations

\begin{tabular}{|c|c|c|c|}
\hline & $\begin{array}{l}\text { BTA } \\
(n=59)\end{array}$ & $\begin{array}{l}\text { Non-BTA } \\
(\mathrm{n}=337)\end{array}$ & $\begin{array}{l}\text { p Value; } \\
\text { OR }(95 \% \mathrm{Cl})\end{array}$ \\
\hline Female sex, n (\%) & $43(73)$ & $212(63)$ & \\
\hline Age (years), mean $\pm S D$ & $56 \pm 13$ & $57 \pm 14$ & \\
\hline fPCA, n (\%) & $2(3)$ & $79(23)$ & $\begin{array}{l}<0.001 ; 0.11 \\
(0.03 \text { to } 0.48)\end{array}$ \\
\hline Bilateral & $1(2)$ & $10(3)$ & 0.26 \\
\hline Partial unilateral & $2(3)$ & $33(10)$ & \\
\hline \multicolumn{4}{|c|}{ Type of fusion, $\mathrm{n} / \mathrm{n}$ evaluated $(\%)^{*}$} \\
\hline Symmetrical cranial & 29/59 (49) & $211 / 335(63)$ & $\begin{array}{l}0.04 ; 0.57 \\
\text { (0.33 to } 0.99)\end{array}$ \\
\hline Symmetrical caudal & $14 / 59(24)$ & $21 / 335(6)$ & $\begin{array}{l}<0.001 ; 4.65 \\
\text { (2.21 to } 9.80)\end{array}$ \\
\hline Asymmetrical & $16 / 59(27)$ & 103/335 (31) & 0.58 \\
\hline
\end{tabular}


Figure 2 Digital subtraction angiography-right unilateral partial fetal-type posterior cerebral artery ( $\mathrm{FPCA}$ ) in patient with basilar tip aneurysms (BTA). (A) Posteroanterior view after right internal carotid artery (ICA) injection shows opacification of the ipsilateral PCA (black arrow, fPCA); there is also partial filling of the BTA (asterisk) through a hypoplastic right P1 segment (dashed arrow).

(B) Posteroanterior view after left ICA injection with opacification of both the anterior cerebral artery and ipsilateral middle cerebral artery. There is no filling of the posterior circulation.
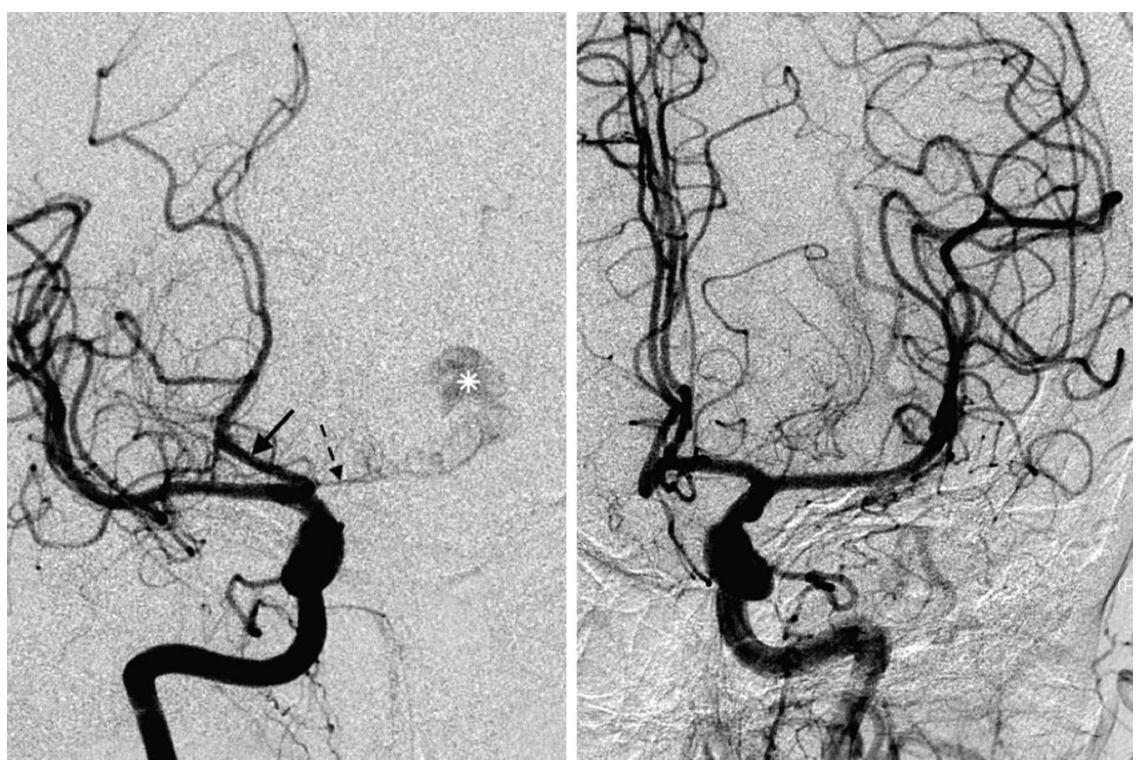

\section{DISCUSSION}

In our study, BTA were significantly associated with the presence of both P1 segments, and the frequency of fPCA was significantly lower in the BTA group than in patients without BTA. This finding is in line with the known the influence of anatomical factors on arterial hemodynamics ${ }^{14} 15$ and aneurysm formation.

Anatomical variants of the circle of Willis are common, and some have long been associated with increased incidence of intracranial aneurysms - namely, of the anterior circulation, supporting the idea that vascular anatomy influences aneurysm formation. $^{16} 17$

There are fewer studies concerning posterior circulation variants, with varying results. Kayembe et $a l,{ }^{16}$ found no increased incidence of fPCA in the aneurysm group compared with controls, but only four of the 44 aneurysms studied involved the basilar tip. More recently, Can et al, ${ }^{10}$ found that a smaller BA diameter and a larger P1-P1 angle were associated with a higher incidence of BTA, but anatomical variants of the circle of Willis were not assessed. Campos et al, ${ }^{18}$ identified P1 agenesis in $2.8 \%$ of 47 patients with BTA, but hypoplastic P1 segments were not assessed and no data on the prevalence of those variants in individuals without BTA were given. In another study investigating the effect of anatomical variations on the incidence of aneurysm recurrence after treatment, Songsaeng et al, ${ }^{19}$ found a positive association between APCA and recurrence of posterior communicating artery aneurysms. To our knowledge, this is the first study to examine the specific association of persistent fPCA and aneurysms of the basilar apex.

It has been established in animal and computational models ${ }^{69}$ that hemodynamic forces, especially wall shear stress, can lead to the formation of saccular aneurysms, both by mechanically affecting the vessel wall and inducing molecular changes that modify it. ${ }^{689}$ Hemodynamic stress is highest at the bifurcation apex of a vessel, such as the tip of the BA. ${ }^{4}{ }^{8}$ It is also known that in subjects with unilateral or bilateral fPCA, the
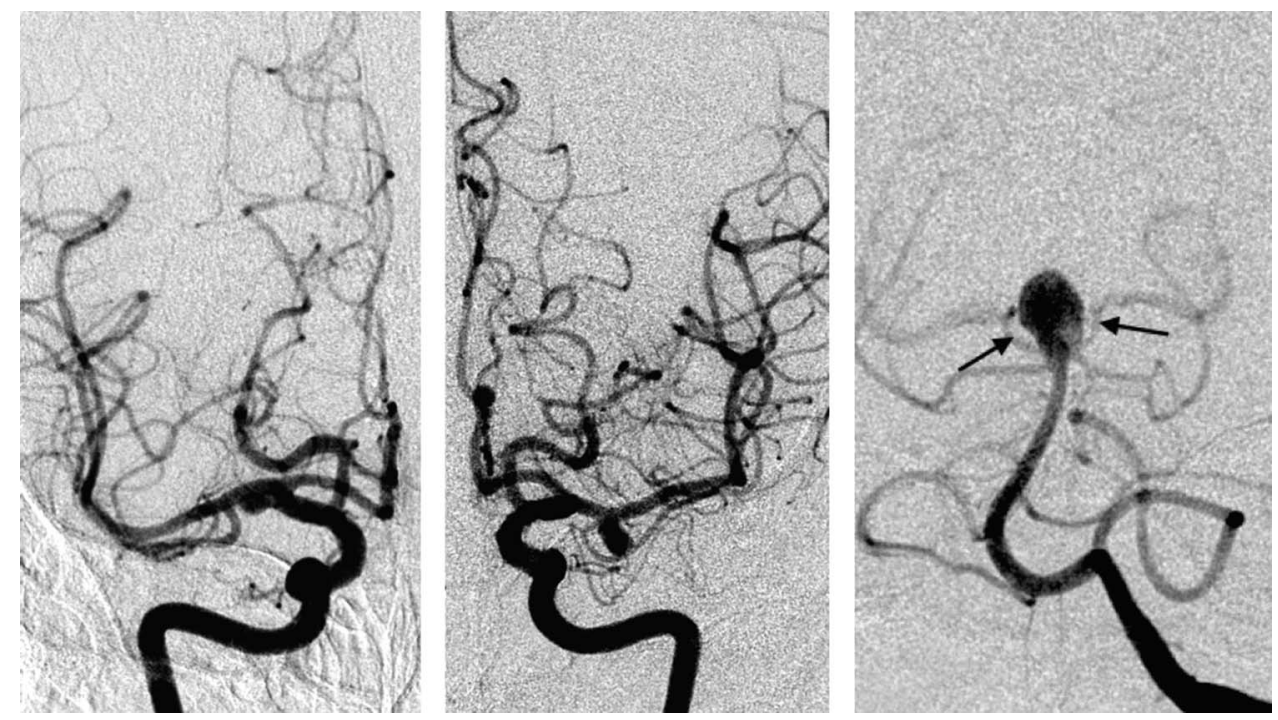

Figure 3 Bilateral partial fetal-type posterior cerebral artery ( $(P C A)$. Anteroposterior projections after contrast injection on the right (A) and left (B) internal carotid artery depict opacification of the anterior circulation and PCA bilaterally, via posterior communicating arteries. (C) Posteroanterior projection after left vertebral artery contrast injection shows presence of hypoplastic P1 segments bilaterally (black arrows). 
flow rate in the BA is decreased, in comparison with corresponding flow values for a circle of Willis with anterograde feeding of the PCAs from the BA. ${ }^{14}{ }^{15}$ It would hence be logical to assume that the presence of fPCA, by both reducing the blood flow in the BA, and rendering the high-flow bifurcation into a lower pressure bifurcation, would be associated with a lower incidence of BTA.

In a total of 59 patients with BTA assessed in our study, no complete fPCA were found, with all patients presenting a P1 segment. Two patients (3.4\%) presented partial fPCA, one bilateral and one unilateral right, which was significantly lower than the frequency in the control group $(\mathrm{p}<0.001)$. We did not study the relation between P1 segment diameter and aneurysm size.

Although there is a strong statistical significance, it is not possible to extrapolate from our findings that fPCA and aneurysms of the BA apex are mutually exclusive. However, it might be argued that this anatomical variant bestows a relative protection against developing saccular BTA, either owing to wall stress reduction or in combination with other factors already discussed in the literature, such as the P1-P1 angle. We believe that PPCA as an anatomical parameter, with its inherent associated hemodynamic consequences, may be a useful tool in predicting the risk of BTA formation. As sheer stress also influences growth and rupture, ${ }^{4}$ fPCA might also be a potential protective factor in patients with existing BTA.

A study of the BA fusion type, showed a higher prevalence of caudal fusion in the BTA group than in controls, which was statistically significant. The relatively higher frequency of caudal BA fusion in patients with BTA is in accordance with previously published data ${ }^{18} 19$ and our findings reinforce the importance of BA fusion type in the formation of BTA.

From a treatment perspective, recognition of variants is paramount for endovascular planning and follow-up. Our studies as well as previous publications demonstrate that in most patients with BTA, P1 segments are patent, ${ }^{18}$ allowing for stent placement if needed during treatment.

Our study has some limitations, mainly related to its retrospective design and the small sample size. Nevertheless, given the lower incidence of BTA, it is a relatively large BTA sample in comparison with previously published series. ${ }^{16-19}$ In addition, our control group did not comprise healthy individuals, but patients who underwent DSA for a number of different and heterogeneous pathologies. However, we have no reason to believe that the incidence of posterior circulation variants in these individuals would differ from that of the general population, and our results for fPCA are similar to those of previous reports. ${ }^{12} 13$

In conclusion, we found a statistically significant association between the absence of a PPCA and BTA. The presence of a fPCA could be an additional morphological parameter to consider when assessing the probability of aneurysm formation in high-risk patients.

Further studies, including computational flow studies, would be needed to assess the probable protective effect of fPCA against the formation of saccular aneurysms at the basilar apex.
Contributors MCD: project development, data collection, manuscript writing, final approval of the version to be published. IF: project development, manuscript writing, final approval of the version to be published. SPD: manuscript writing, statistical analysis, final approval of the version to be published. JN: data collection, final approval of the version to be published. JP: data collection, manuscript correction, final approval of the version to be published. JR: project development, data collection, final approval of the version to be published.

Competing interests None declared.

Ethics approval Approved by the ethics committee of Centro Hospitalar de Lisboa Central.

Informed consent All patients gave informed consent before inclusion in this study. Provenance and peer review Not commissioned; externally peer reviewed.

Data sharing statement For any questions or further data requests, contact first author.

\section{REFERENCES}

1 Caranci F, Briganti F, Cirillo L, et al. Epidemiology and genetics of intracranial aneurysms. Eur J Radiol 2013;82:1598-605.

2 Brisman JL, Song JK, Newell DW. Cerebral aneurysms. N Engl J Med 2006;355:928-39.

3 Greving JP, Wermer MJ, Brown RD, et al. Development of the PHASES score for prediction of risk of rupture of intracranial aneurysms: a pooled analysis of six prospective cohort studies. Lancet Neurol 2014;13:59-66.

4 Francis SE, Tu J, Qian Y, et al. A combination of genetic, molecular and haemodynamic risk factors contributes to the formation, enlargement and rupture of brain aneurysms. J Clin Neurosci 2013;20:912-18.

5 Bacigaluppi S, Piccinelli M, Antiga L, et al. Factors affecting formation and rupture of intracranial saccular aneurysms. Neurosurg Rev 2014;37:1-14.

6 Gao L, Hoi Y, Swartz DD, et al. Nascent aneurysm formation at the basilar terminus induced by hemodynamics. Stroke 2008;39:2085-90.

7 Feigin V, Parag V, Lawes CM, et al. Smoking and elevated blood pressure are the most important risk factors for subarachnoid hemorrhage in the Asia-Pacific region: an overview of 26 cohorts involving 306,620 participants. Stroke 2005;36:1360-5.

8 Penn DL, Komotar RJ, Sander Connolly E. Hemodynamic mechanisms underlying cerebral aneurysm pathogenesis. J Clin Neurosci 2011;18:1435-8.

9 Foutrakis GN, Yonas H, Sclabassi RJ. Saccular aneurysm formation in curved and bifurcating arteries. AJNR Am J Neuroradiol 1999;20:1309-17.

10 Can A, Mouminah A, Ho AL, et al. Effect of vascular anatomy on the formation of basilar tip aneurysms. Neurosurgery 2015;76:62-6.

11 Lasjaunias P, Berenstein A, TerBrugge K. Clinical vascular anatomy and variations. Springer Science \& Business Media, 2013.

12 Kovač JD, Stanković A, Stanković D, et al. Intracranial arterial variations: a comprehensive evaluation using CT angiography. Med Sci Monit 2014;20:420-7.

13 van Raamt AF, Mali WP, van Laar PJ, et al. The fetal variant of the circle of Willis and its influence on the cerebral collateral circulation. Cerebrovasc Dis 2006:22:217-24.

14 Tanaka H, Fujita N, Enoki T, et al. Relationship between variations in the circle of Willis and flow rates in internal carotid and basilar arteries determined by means of magnetic resonance imaging with semiautomated lumen segmentation: reference data from 125 healthy volunteers. AJNR Am J Neuroradiol 2006;27:1770-5.

15 Hendrikse J, van Raamt AF, van der Graaf $Y$, et al. Distribution of cerebral blood flow in the circle of Willis. Radiology 2005;235:184-9.

16 Kayembe KNT, Sasahara M, Hazama F. Cerebral aneurysms and variations in the circle of Willis. Stroke 1984;15:846-50.

17 Tarulli E, Fox AJ. Potent risk factor for aneurysm formation: termination aneurysms of the anterior communicating artery and detection of A1 vessel asymmetry by flow dilution. AJNR Am J Neuroradiol 2010;31:1186-91.

18 Campos C, Churojana A, Rodesch G, et al. Basilar tip aneurysm and basilar tip anatomy. Interv Neuroradiol 1998;4:121-5.

19 Songsaeng D, Geibprasert S, Willinsky R, et al. Impact of anatomical variations of the circle of Willis on the incidence of aneurysms and their recurrence rate following endovascular treatment. Clin Radiol 2010;65:895-901. 


\section{JIS Low prevalence of fetal-type posterior cerebral artery in patients with basilar tip aneurysms}

Mariana C Diogo, Isabel Fragata, Sara P Dias, Joana Nunes, Jaime

Pamplona and João Reis

J Neurolntervent Surg published online June 30, 2016

Updated information and services can be found at:

http://jnis.bmj.com/content/early/2016/06/30/neurintsurg-2016-01250

3

These include:

References This article cites 18 articles, 7 of which you can access for free at: http://jnis.bmj.com/content/early/2016/06/30/neurintsurg-2016-01250 3\#BIBL

Email alerting

Receive free email alerts when new articles cite this article. Sign up in the service box at the top right corner of the online article.

Topic Articles on similar topics can be found in the following collections

Collections

Neuroimaging (126)

\section{Notes}

To request permissions go to:

http://group.bmj.com/group/rights-licensing/permissions

To order reprints go to:

http://journals.bmj.com/cgi/reprintform

To subscribe to BMJ go to:

http://group.bmj.com/subscribe/ 